\title{
B-2-Adrenergic receptor gene polymorphism confers susceptibility to Graves disease
}

\author{
KRYSTIAN JAZDZEWSKI ${ }^{1,2,4}$, TOMASZ BEDNARCZUK ${ }^{3}$, MAGDALENA STEPNOWSKA ${ }^{2}$, \\ SANDYA LIYANARACHCHI ${ }^{4}$, KRYSTYNA SUCHECKA-RACHON ${ }^{1}$, \\ JANUSZ LIMON $^{2}$ and KRZYSZTOF NARKIEWICZ ${ }^{1}$
}

\begin{abstract}
Departments of ${ }^{1}$ Hypertension and Diabetology, ${ }^{2}$ Biology and Genetics, Medical University of Gdansk, Debinki 1, 80-211 Gdansk, Poland; ${ }^{3}$ Department of Endocrinology, Medical Research Center, Polish Academy of Science, Banacha 1A, 02-097 Warsaw, Poland; ${ }^{4}$ Human Cancer Genetics Program, Comprehensive Cancer Center, Ohio State University, 420 West 12th Avenue, Columbus, Ohio 43221, USA
\end{abstract}

Received June 14, 2006; Accepted August 21, 2006

\begin{abstract}
Graves disease (GD) is an autoimmune disorder with genetic predisposition. The polymorphisms $47 \mathrm{~A} \rightarrow \mathrm{G}$ (Arg16Gly) and $79 \mathrm{C} \rightarrow \mathrm{G}$ (Gln27Glu) of the adrenergic $B-2$ receptor $(A D R B 2)$ gene in the $5 \mathrm{q} 32$ region affect the functional reaction to adrenergic stimulation, which contributes to the regulation of immunological response. The $-367 \mathrm{~T} \rightarrow \mathrm{C}$ polymorphism within the 5'-leading regulatory sequence affects $A D R B 2$ transcriptional activity. The aim of the present study was to investigate whether $A D R B 2$ gene variants are associated with susceptibility to GD. All polymorphisms were studied in Polish GD patients $(n=300)$ and healthy control subjects without a family history of autoimmune disorders $(n=301)$. Genotypes were determined by the MassARRAYTM system (Sequenom, San Diego, CA). Gly16 and Gln27 allele frequencies were $61.4 \%$ and $55.2 \%$ among healthy controls, almost the same as previously reported in 4441 white participants of a cardiovascular health study. We found a higher risk of GD in Gln27 carriers (CC or CG genotypes) than in Glu27 homozygous (GG genotype) participants $\left(\mathrm{OR}=1.99,95 \%\right.$ CI: $\left.1.27-3.12, \mathrm{p}=0.003, \mathrm{p}_{\text {corr }}=0.03\right)$. The frequency of the $79 \mathrm{GG}$ protective genotype was significantly smaller in the GD patients without symptoms of Graves
\end{abstract}

Correspondence to: Dr Krystian Jazdzewski, Comprehensive Cancer Center, Ohio State University, 606 TMRF, 420 West 12th Avenue, Columbus, Ohio 43221, USA

E-mail: krystian.jazdzewski@osumc.edu

Abbreviations: GD, Graves disease; GO, Graves ophthalmopathy; ADRB2, B2-adrenergic receptor; SNP, single nucleotide polymorphism; LD, linkage disequilibrium; CAS, ophthalmopathy clinical activity score

Key words: ß-2-adrenergic receptor gene, polymorphism, haplotype, Graves disease, ophthalmopathy, autoimmunity, genetic predisposition ophthalmopathy compared to controls $(10 \%$ vs $22 \%$, OR=0.41, 95\% CI: $\left.0.234-0.706, \mathrm{p}=0.0017, \mathrm{p}_{\text {corr }}=0.015\right)$. We didn't find any association of $-367 \mathrm{~T} \rightarrow \mathrm{C}$ or $47 \mathrm{~A} \rightarrow \mathrm{G}$ genotypes/alleles with Graves disease, however, haplotype analysis has shown a significant difference in haplotype distribution between patients and controls (the global $\mathrm{p}=0.001$ ) with increased $-367 \mathrm{~T} / 47 \mathrm{~A} /$ 79C haplotype frequency in GD patients compared to controls (34\% vs $\left.25 \%, \mathrm{p}=0.00073, \mathrm{p}_{\text {corr }}=0.0044\right)$. In conclusion, Gln27 carriers (79CC or $79 \mathrm{GC}$ genotypes) have increased risk of Graves disease. Our results suggest that ADRB2 plays a role in susceptibility to Graves disease in humans.

\section{Introduction}

Graves disease (GD) is an autoimmune disorder with inflammatory cytokine imbalance and varying degrees of hyperthyroidism and ophthalmopathy (Graves ophthalmopathy, GO). GD is considered to be a complex trait to which genetic, environmental, and demographic factors contribute interactively (1). Recent genome-wide searches have provided evidence for linkage to loci on multiple chromosomes, however the significance of a particular locus has rarely been confirmed in more than one population (2). Association studies have shown that major histocompatibility complex (MHC) alleles (3), the cytotoxic T lymphocyte antigen-4 (CTLA-4) gene (4-6) and the lymphoid tyrosine phosphatase (PTPN22/LYP) gene (7) confer risk for GD. Products from all of those genes are potentially involved in antigen presentation and $\mathrm{T}$ cell recognition. The list of additional candidate genes comprises thyrotropin receptor (TSHR), CD40, interferon- $\gamma$ (IFN- $\gamma$ ), tumor necrosis factor- $\alpha$ (TNF- $\alpha$ ) and interleukin (IL)-13, but their contribution to the susceptibility to GD awaits confirmation.

The adrenergic $3-2$ receptor (ADRB2) is a $\mathrm{G}$ proteincoupled receptor that mediates the actions of catecholamines in multiple tissues (8). ADRB2 located on T helper $1\left(\mathrm{~T}_{\mathrm{H}} 1\right)$ cells is an important immunoregulatory factor which upon activation decreases the level of Th1-specific cytokines such as IFN- $\gamma$, IL-12, TNF- $\alpha$ and IL-1 $\beta$, which leads to the over- 
representation of $\mathrm{T}_{\mathrm{H}} 2$ cytokines such as IL-4 and IL-13 and the domination of humoral immune activity (9). In thyroid autoimmunity, a mixed $\mathrm{T}_{\mathrm{H}} 1$ and $\mathrm{T}_{\mathrm{H}} 2$ pattern has been found in GD tissue samples, however some studies have shown a $\mathrm{T}_{\mathrm{H}} 1$ response in Hashimoto thyroiditis and $\mathrm{T}_{\mathrm{H}} 2$ response in GD (10-13). It was recently reported that both the population of $T_{H} 1$ cells and the ratio of Th1/Th2 cells were lower in GD and higher in GO as compared to those in controls (14). In the same study the authors found a positive correlation of Th1 cell percentage and Th1/Th2 cell ratio with clinical activity score (CAS) in GO (14). Thus, the adrenergic B-2 receptor acting as selective suppressor of $\mathrm{T}_{\mathrm{H}} 1$-cellular immunity axis may be a potential candidate contributing to the development of GD and/or GO. Of note, the ADRB2 gene is located in the 5q32-3 region linked to GD in three linkage studies (15-17).

Several single nucleotide polymorphisms (SNP) have been detected within the $A D R B 2$ gene intronless sequence and its $5^{\prime}$ upstream regulatory region. In particular, a few of them present both evidence of functional relevance and a high degree of heterozygosity, which are the basis for a possible pathophysiological role in the modulation of 'complex' traits. The 47A $\rightarrow \mathrm{G}$ (Arg16Gly, dbSNP125: rs17859732) and the 79C $\rightarrow$ G (Gln27Glu, dbSNP125: rs17859733) polymorphisms influence a rate of agonist-induced receptor down-regulation (18-20). The haplotype within the 5' upstream regulatory region comprising the $-367 \mathrm{~T} \rightarrow \mathrm{C}(\mathrm{dbSNP} 125:$ rs 11959427) polymorphism impacts promoter activity and transcription rate $(21,22)$.

The $A D R B 2$ gene SNPs have been reported to be associated with susceptibility to some inflammatory disorders such as asthma $(23,24)$ and cardiovascular diseases such as coronary heart disease $(25)$, congestive heart failure $(26,27)$ and hypertension in diabetics (28). No data concerning $A D R B 2$ gene association with Graves disease have been reported.

The aim of the present study was to investigate whether polymorphisms of the $A D R B 2$ gene are associated with the development of GD and/or GO.

\section{Materials and methods}

Subjects. We studied a total of 300 Polish patients (237 females and 63 males, aged 6-78 years old, mean age 41.1 \pm 15.3 years) with Graves disease diagnosed based on the presence of hyperthyroidism, diffuse goiter, detectable thyroid-stimulating hormone receptor autoantibodies (TRAK Lumitest, BRAHMS Diagnostica, Germany) and/or increased radioiodine uptake, as described previously (29). Thyroid-associated ophthalmopathy (GO) was classified according to the clinical activity score system recommended by the American Thyroid Association (ATA) Committee (30). Of the GD patients, 108 (82 females and 26 males, mean age $45.1 \pm 14.3$ years) showed ophthalmopathy defined as ATA class III or greater and were classified as $\mathrm{GO}(+)$. One hundred and ninety-two patients showed no ophthalmopathy (ATA class 0), signs of ophthalmopathy without symptoms (ATA class I), or only soft tissue involvement (ATA class II). The control group comprised 301 healthy unrelated Polish individuals (206 females and 95 males; aged 15-82 years; mean age $39.3 \pm 13.6$ years) with no family history of autoimmune diseases. All study participants were white and of Polish origin. The research program was approved by the local ethics committee, and all subjects provided written informed consent for genetic studies.

Genotyping. Genomic DNA was extracted from peripheral blood using standard techniques. All SNPs were defined by PCR and MassARRAY ${ }^{\mathrm{TM}}$ system (Sequenom, San Diego, CA). PCR was performed using 2 ng genomic DNA in $5 \mu \mathrm{l}$ reaction with a mixture containing $1 \mathrm{X}$ dilution of $10 \mathrm{X}$ PCR buffer (Applied Biosystems, Foster City, CA), $200 \mathrm{nmol}$ of each primer, $0.4 \mathrm{mmol}$ dATP, dGTP, dTTP, dCTP, and $0.5 \mathrm{U}$ of Amplitaq Gold DNA polymerase (Applied Biosystems) under the following conditions: $94^{\circ} \mathrm{C}$ for $15 \mathrm{~min}$, followed by 45 cycles at $95^{\circ} \mathrm{C}$ for $20 \mathrm{sec}, 56^{\circ} \mathrm{C}$ for $30 \mathrm{sec}, 72^{\circ} \mathrm{C}$ for $1 \mathrm{~min}$, and a final extension step $72^{\circ} \mathrm{C}$ for $3 \mathrm{~min}$. MassARRAY Homogenous MassEXTEND ${ }^{\mathrm{TM}}$ (hME) assay (Sequenom) was conducted according to the manufacturer's instructions. The primer sequences are available upon request.

Statistical analysis. Statistical analysis was conducted using R software (http://cran.r-project.org) with additional packages 'survival' and 'genetics'. The Chi-square test was applied to check the homogeneity in genotype frequency distributions between the patient group and controls. If any of the expected counts was $<5$, the Fisher's exact test was applied. $p$ values were corrected by multiplying by the number of alleles, genotypes or haplotypes tested (Bonferroni correction). A corrected $\mathrm{p}$ value $\left(\mathrm{p}_{\text {corr }}\right)$ of $<0.05$ was considered statistically significant. Genotype frequencies in all groups were checked for the Hardy-Weinberg equilibrium using the Chi-square test. Cox proportional hazard regression model was applied to estimate any association between the GD age of onset and the genotypes. ANOVA analysis was used to compare differences in age of disease onset between patient subgroups. Odds ratios were calculated by Woolf's method. The population haplotype frequency distribution was estimated from population genotype data by PHASE version 2.02 software $(31,32)$. The differences in estimated haplotype frequencies were analyzed by a case-control permutation test with 1000 iterations implemented in the PHASE software package. Linkage disequilibrium (LD) was estimated for all possible SNP pairs using two-side LD parameters: D, D' and $r^{2}$. The LD coefficient D represents the difference between the observed frequency of a two-locus haplotype and the frequency it would be expected to show if the alleles were segregating at random. The $\mathrm{D}^{\prime}$ parameter is calculated by dividing $\mathrm{D}$ by its maximum possible value given the allele frequencies at the two loci. A D' value of 1 or -1 indicates that two SNPs are in complete LD. Power calculation was performed using PAWE software (http://linkage.rockefeller. edu/pawe $(33,34)$.

\section{Results}

Association of ADRB2 gene polymorphisms with Graves disease. The genotype distributions of all SNPs for both groups (cases and controls) were consistent with the HardyWeinberg equilibrium. Genotype frequencies for ADRB2 gene polymorphisms are summarized in Table I. Allele frequencies for $A D R B 2$ gene polymorphisms are summarized in Table II. 
Table I. Genotype frequencies of the $A D R B 2$ gene polymorphisms in healthy subjects and patients with Graves disease with or without ophthalmopathy.

\begin{tabular}{lcccc}
\hline & $\begin{array}{c}\text { Healthy subjects } \\
\mathrm{n}=301\end{array}$ & $\begin{array}{c}\text { GD total } \\
\mathrm{n}=300\end{array}$ & $\begin{array}{c}\text { Ophthalmopathy } \\
\text { ATA class 0-II } \\
\mathrm{n}=192\end{array}$ & $\begin{array}{c}\text { Ophthalmopathy } \\
\text { ATA class III-VI } \\
\mathrm{n}=108\end{array}$ \\
\hline$-367 \mathrm{~T} \rightarrow \mathrm{C}$ & & & $40(0.47)$ \\
$\mathrm{TT}$ & & & $59(0.40)$ & $34(0.40)$ \\
$\mathrm{CT}$ & $98(0.35)$ & $99(0.42)$ & $69(0.46)$ & $11(0.13)$ \\
$\mathrm{CC}$ & $128(0.46)$ & $103(0.44)$ & $21(0.14)$ & $20(0.19)$ \\
$47 \mathrm{~A} \rightarrow \mathrm{G}$ & $51(0.18)$ & $32(0.14)$ & $29(0.16)$ & $52(0.49)$ \\
$\mathrm{AA}$ & & & $92(0.51)$ & $34(0.32)$ \\
$\mathrm{AG}$ & $39(0.14)$ & $49(0.17)$ & $59(0.33)$ & $39(0.37)$ \\
$\mathrm{GG}$ & $139(0.49)$ & $144(0.50)$ & & $49(0.47)$ \\
$79 \mathrm{C} \rightarrow \mathrm{G}$ & $103(0.37)$ & $93(0.33)$ & $66(0.36)$ & $17(0.16)$ \\
$\mathrm{CC}$ & & & $99(0.54)$ & $19(0.10)^{\mathrm{b}}$ \\
$\mathrm{CG}$ & $91(0.32)$ & $105(0.36)$ & $148(0.51)$ & \\
$\mathrm{GG}$ & $128(0.46)$ & $36(0.12)^{\mathrm{a}}$ & & \\
\hline
\end{tabular}

${ }^{\mathrm{a} C h i}$-square test, GG vs CC+GC, $\chi^{2}=8.57, d f=1, \mathrm{p}=0.0034, \mathrm{p}_{\text {corr }}=0.030$. ${ }^{\mathrm{b}}$ Chi-square test, $\mathrm{GG}$ vs $\mathrm{CC}+\mathrm{GC}, \chi^{2}=9.85, d f=1, \mathrm{p}=0.0017, \mathrm{p}_{\text {corr }}=0.015$. GD, Graves disease; ATA, American Thyroid Association. Values in parentheses represent proportion of individuals expressed as a percentage.

Table II. Allelic frequencies of the ADRB2 gene polymorphisms in healthy subjects and patients with Graves disease with or without ophthalmopathy.

\begin{tabular}{|c|c|c|c|c|}
\hline & $\begin{array}{l}\text { Healthy subjects } \\
\qquad \mathrm{n}=301\end{array}$ & $\begin{array}{l}\text { GD total } \\
n=300\end{array}$ & $\begin{array}{c}\text { Ophthalmopathy } \\
\text { ATA class 0-II } \\
\text { n=192 }\end{array}$ & $\begin{array}{c}\text { Ophthalmopathy } \\
\text { ATA class III-VI } \\
n=108\end{array}$ \\
\hline \multicolumn{5}{|l|}{$-367 \mathrm{~T} \rightarrow \mathrm{C}$} \\
\hline $\mathrm{T}$ allele & $324(0.58)$ & $301(0.64)$ & $187(0.63)$ & $114(0.67)$ \\
\hline $\mathrm{C}$ allele & $230(0.42)$ & $167(0.36)$ & $111(0.37)$ & $56(0.33)$ \\
\hline \multicolumn{5}{|l|}{$47 \mathrm{~A} \rightarrow \mathrm{G}$} \\
\hline A allele & $217(0.39)$ & $242(0.42)$ & $150(0.42)$ & $92(0.43)$ \\
\hline $\mathrm{G}$ allele & $345(0.61)$ & $330(0.58)$ & $210(0.58)$ & $120(0.57)$ \\
\hline \multicolumn{5}{|l|}{$79 \mathrm{C} \rightarrow \mathrm{G}$} \\
\hline $\mathrm{C}$ allele & $310(0.55)$ & $358(0.62)$ & $231(0.63)$ & $127(0.60)$ \\
\hline $\mathrm{G}$ allele & $252(0.45)$ & $220(0.38)^{\mathrm{a}}$ & $137(0.37)^{\mathrm{b}}$ & $83(0.40)$ \\
\hline
\end{tabular}

${ }^{\mathrm{a} C h i}$-square test, $\chi^{2}=5.12, d f=1, \mathrm{p}=0.024, \mathrm{p}_{\text {corr }}=0.14$, power $69 \%$. ${ }^{\mathrm{b}}$ Chi-square test, $\chi^{2}=4.99, d f=1, \mathrm{p}=0.026, \mathrm{p}_{\text {corr }}=0.16$, power $71 \%$. GD, Graves disease; ATA, American Thyroid Association. Values in parentheses represent proportion of individuals expressed as a percentage.

We found a higher risk of GD in Gln27 carriers (CC or CG genotypes) than in Glu27 homozygous (GG genotype) participants $(\mathrm{OR}=1.99,95 \% \mathrm{CI}: 1.27-3.12, \mathrm{p}=0.003$, $\left.\mathrm{p}_{\text {corr }}=0.03\right)$. The $79 \mathrm{C}$ allele frequency appeared to be greater in the GD patients compared to the controls, but this difference was not significant $(62 \%$ vs $55 \%$; OR $=1.32,95 \%$ CI: 1.05 $1.79, \mathrm{p}=0.024, \mathrm{p}_{\text {corr }}=0.14$, power $69 \%$ ).

We didn't find any association of $-367 \mathrm{~T} \rightarrow \mathrm{C}$ or $47 \mathrm{~A} \rightarrow \mathrm{G}$ genotypes/alleles with Graves disease (power $<57 \%$ ).
There were six haplotypes of $A D R B 2$ gene polymorphisms in the present study (Table III). Haplotype analysis showed a significant difference in haplotype frequency distribution between patients and controls (the global $\mathrm{p}=0.001$ ) with increased $-367 \mathrm{~T} / 47 \mathrm{~A} / 79 \mathrm{C}$ haplotype frequency in GD patients compared to controls $(34 \%$ vs $25 \%, \mathrm{OR}=1.55,95 \%$ CI: $\left.1.208-1.999, \mathrm{p}=0.00073, \mathrm{p}_{\text {corr }}=0.0044\right)$.

The linkage disequilibrium (LD) among $A D R B 2$ gene SNPs in GD is summarized in Table IV. We found marked LD 
Table III. Estimated frequencies of the $A D R B 2$ gene haplotypes in healthy subjects and patients with Graves disease.

\begin{tabular}{ccccccc}
\hline & \multirow{2}{*}{$\begin{array}{c}\text { Haplotypes } \\
\text { (positions -367/47/79) }\end{array}$} & \multicolumn{2}{c}{ Healthy subjects } & & \multicolumn{2}{c}{ Graves disease } \\
\cline { 3 - 3 } & & Frequency & Standard error & & Frequency & Standard error \\
\hline 1 & TAC & 0.244 & 0.010 & & $0.334^{\text {a }}$ & 0.010 \\
2 & CGG & 0.228 & 0.008 & & 0.253 & 0.011 \\
3 & CGC & 0.189 & 0.008 & & 0.117 & 0.011 \\
4 & TAG & 0.143 & 0.009 & & 0.082 & 0.010 \\
5 & TGC & 0.121 & 0.008 & & 0.166 & 0.008 \\
6 & TGG & 0.073 & 0.008 & & 0.043 & 0.008 \\
\hline
\end{tabular}

The differences in estimated haplotype frequencies were analyzed by a case-control permutation test with 1000 iterations implemented in the PHASE software package; the global $\mathrm{p}=0.001$. ${ }^{\mathrm{a}}$ Chi-square test, $\chi^{2}=11.41, d f=1, \mathrm{p}=0.00073, \mathrm{p}_{\text {corr }}=0.0044$.

Table IV. The linkage disequilibrium (LD) among ADRB2 gene polymorphisms in patients with Graves disease.

\begin{tabular}{rccc}
\hline & $-367 \mathrm{~T}>\mathrm{C}$ & $47 \mathrm{~A}>\mathrm{G}$ & $79 \mathrm{C}>\mathrm{G}$ \\
\hline$-367 \mathrm{~T}>\mathrm{C}$ & & $\mathrm{D}^{\prime}=0.97$ & $\mathrm{D}^{\prime}=0.67$ \\
$47 \mathrm{~A}>\mathrm{G}$ & $\mathrm{r}^{2}=0.62$ & & $\mathrm{D}^{\prime}=0.60$ \\
$79 \mathrm{C}>\mathrm{G}$ & $\mathrm{r}^{2}=0.64$ & $\mathrm{r}^{2}=0.41$ & \\
\hline
\end{tabular}

between $-367 \mathrm{~T} \rightarrow \mathrm{C} / 47 \mathrm{~A} \rightarrow \mathrm{G}$ polymorphisms $\left(\mathrm{D}^{\prime}=0.97, \mathrm{r}^{2}=0.62\right)$, also for $367 \mathrm{~T} \rightarrow \mathrm{C} / 79 \mathrm{C}>\mathrm{G}$ polymorphisms $\left(\mathrm{D}^{\prime}=0.67, \mathrm{r}^{2}=0.64\right)$ and $47 \mathrm{~A}>\mathrm{G} / 79 \mathrm{C}>\mathrm{G}$ polymorphisms $\left(\mathrm{D}^{\prime}=0.60, \mathrm{r}^{2}=0.41\right)$.

Association between the ADRB2 gene polymorphisms and Graves ophthalmopathy. The frequency of the 79GG protective genotype was significantly smaller in the GD patients without GO (ATA class $\leq \mathrm{II}, \mathrm{n}=192$ ) compared to the controls ( $10 \%$ vs $22 \%$, OR $=0.41,95 \%$ CI: $0.234-0.706$, $\mathrm{p}=0.0017, \mathrm{p}_{\text {corr }}=0.015$; Table I). The $79 \mathrm{G}$ allele frequency appeared to be smaller in the GD patients without GO compared to the controls, but this difference was not significant $(37 \%$ vs $45 \%$; OR $=0.73,95 \%$ CI: $0.558-0.955$, $\mathrm{p}=0.026, \mathrm{p}_{\text {corr }}=0.16$, power $71 \%$; Table II).

Age of onset. The mean age of GD onset was 37 years for females and 42 years for males; this difference was significant $(p=0.015)$. The results of the Cox proportional hazards regression indicated no association between age of GD onset and any genotype ( $>>0.3)$. Patients with ophthalmopathy (ATA $\geq$ III) were significantly older (mean 41 years) than cases without evident eye symptoms (ATA $\leq$ II, mean 36 years) with $\mathrm{p}=0.002$. There was no difference in age of GO onset between genders $(\mathrm{p}=0.11)$.

\section{Discussion}

The evidence for genetic involvement in the pathogenesis of GD disease comes from the study of twins, in addition to the observation of familial clustering of the disease. In the study of 8966 Danish twin pairs Brix et al found a crude concordance rate of 35\% for MZ pairs and 3\% for DZ pairs, and estimated that $79 \%$ of the liability to the development of GD is attributable to genetic factors (35). Although several susceptibility loci were noted in a linkage analysis performed in multiplex families, the results from only three of them were replicated (chromosomes 5,8 and 20) and only one replication (5q31) was convincing (36). Sakai et al in a genome-wide analysis performed on $123 \mathrm{GD}$ and/or Hashimoto affected Japanese sib-pairs (15) found significant linkage for microsatellite marker D5S436 in the region 5q31 $(\mathrm{LOD}=3.14)$. This result was replicated in 54 Chinese multiplex GD pedigrees with a maximum two-point LOD score of 2.8 for D5S436, and an LOD score of 4.31 for D5S2090, another marker in this region (16). Akamizu et al performed an association study in 440 Japanese GD patients and 218 controls and confirmed a significant association between GD and two more markers in the 5q31-33 region (17). The ADRB2 gene is located $3 \mathrm{Mb}$ downstream from marker D5S436 and $1 \mathrm{Mb}$ downstream from marker D5S2090.

The sympathetic nervous system via $\beta$-2-adrenergic receptors causes selective suppression of the Th1-cellular immunity axis and a shift toward Th2-mediated humoral immunity $(9,37)$. It might be of great importance in GD since this disorder is characterized by an abnormality in immune regulation.

The present report is the first clinical study on the significance of the functional polymorphisms of the ADRB2 gene in Graves disease. We have demonstrated that the Gln27 carriers (CC or GC genotypes) are at a higher risk of GD than Glu27 homozygous participants. Studies of the effects of $A D R B 2$ gene polymorphisms on its product function showed enhanced agonist-induced receptor desensitization (in vitro) in the 16Gly variant and resistance to desensitization in the $27 \mathrm{Glu}$ variant as compared to wild-type alleles (16Arg and Gln27, respectively $(18,19)$. For that reason, our findings may lead to the conclusion that the ADRB2 receptor variant characterized by increased agonist-mediated down-regulation is responsive for susceptibility to GD, but a single SNP result should be considered in terms of larger haplotype, as it is possible that another SNP, linked to Gln27Glu, is of superior functional importance. The Arg16Gly polymorphism, in 
strong linkage disequilibrium with Gln27Glu, seems to play the dominant role, since the 16Gly phenotype was observed regardless of whether the position 27 amino acid was Glu or Gln (38). We performed the haplotype analysis and found the $-367 \mathrm{~T} / 47 \mathrm{~A} / 79 \mathrm{C}$ haplotype to be substantially more prevalent in GD patients than in controls and thus conferring a higher risk of GD. This haplotype appears to be resistant to agonistinduced receptor desensitization (proved for 47A/79C diplotype) in addition to having a higher 'baseline' expression level (proved for -367T, which always goes with 47A/79C) and therefore appears to represent the highly functional ADRB2 receptor variant. However, this function of the entire -367T/ 47A/79C haplotype needs to be confirmed experimentally (discussed further in ref. 39).

The role of $A D R B 2$ gene polymorphisms as disease risk factors has been demonstrated in asthma $(23,24)$, coronary heart disease (25), congestive heart failure $(26,27)$, hypertension in diabetics (28) and recently in sudden cardiac death (40). Interestingly, the 47A/79C diplotype (Arg16/Gln27) was reported to be associated with an elevated total IgE level in pollen allergy (41). The increased level of IgE is also observed in GD patients. Of note, cigarette smoking, a known environmental factor involved in the development of autoimmune diseases, has a similar to 47A/79C diplotype impact on the sympathetic outflow, i.e. it increases adrenergic action (42).

We speculate that the highly functional ADRB2 receptor variant confers an increased risk for GD by more efficiently polarizing the immune response towards antibody production. Additional studies must be conducted to clarify whether the differences in GD risk are related to the changes in immune response described for the $-367 \mathrm{~T} / 47 \mathrm{~A} / 79 \mathrm{C}$ haplotype, and whether the haplotype is a marker for other determinants of GD risk. Also the final tissue- and time-dependent impact of this haplotype on receptor function is yet to be evaluated (43). We didn't find any direct association of either the Arg16Gly or the $-167 \mathrm{~T} \rightarrow \mathrm{C}$ polymorphism with susceptibility to GD, probably because our study was under-powered to full address this. Since we observed the Gly16 and Gln27 allele frequencies among healthy controls to be $61.4 \%$ and $55.2 \%$, respectively, almost the same as previously reported in 4441 white participants of a cardiovascular health study (40), we report that the control group data was correct.

\section{Acknowledgments}

We thank Dr Albert de la Chapelle for advice and support. This work was supported by the Polish State Committee for Scientific Research (grant no. 3PO5B 155 25). Magdalena Stepnowska was supported by a Ph.D. fellowship from the University of Gdansk, Poland.

\section{References}

1. Vaidya B, Kendall-Taylor P and Pearce SH: The genetics of autoimmune thyroid disease. J Clin Endocrinol Metab 87: 5385-5397, 2002

2. Tomer Y and Davies TF: Searching for the autoimmune thyroid disease susceptibility genes: from gene mapping to gene function. Endocr Rev 24: 694-717, 2003.

3. Schleusener H, Schernthaner G, Mayr WR, et al: HLA-DR3 and HLA-DR5 associated thyrotoxicosis: two different types of toxic diffuse goiter. J Clin Endocrinol Metab 56: 781-785, 1983.
4. Kouki T, Sawai Y, Gardine CA, Fisfalen ME, Alegre ML and DeGroot LJ: CTLA-4 gene polymorphism at position 49 in exon 1 reduces the inhibitory function of CTLA-4 and contributes to the pathogenesis of Graves disease. J Immunol 165: 6606-6611, 2000.

5. Bednarczuk T, Hiromatsu Y, Fukutani T, et al: Association of cytotoxic T-lymphocyte-associated antigen-4 (CTLA-4) gene polymorphism and non-genetic factors with Graves ophthalmopathy in European and Japanese populations. Eur J Endocrinol 148: $13-18,2003$

6. Ueda H, Howson JM, Esposito L, et al: Association of the Tcell regulatory gene CTLA4 with susceptibility to autoimmune disease. Nature 423: 506-511, 2003.

7. Velaga MR, Wilson V, Jennings CE, et al: The codon 620 tryptophan allele of the lymphoid tyrosine phosphatase (LYP) gene is a major determinant of Graves disease. J Clin Endocrinol Metab 89: 5862-5865, 2004.

8. Liggett SB: B2-adrenergic pharmacogenetics. Am J Respir Crit Care Med 161: S197-S201, 2000.

9. Elenkov IJ, Wilder RL, Chrousos GP and Vizi ES: The sympathetic nerve an integrative interface between two supersystems: the brain and the immune system. Pharmacol Rev 52: 595-638, 2000.

10. Heuer M, Aust G, Ode-Hakim S and Scherbaum WA: Different cytokine mRNA profiles in Graves disease, Hashimoto's thyroiditis, and nonautoimmune thyroid disorders determined by quantitative reverse transcriptase polymerase chain reaction (RT-PCR). Thyroid 6: 97-106, 1996.

11. Hidaka Y, Okumura M, Fukata S, et al: Increased serum concentration of interleukin-12 in patients with silent thyroiditis and Graves disease. Thyroid 9: 149-153, 1999.

12. Ajjan RA, Watson PF and Weetman AP: Detection of IL-12, IL-13, and IL-15 messenger ribonucleic acid in the thyroid of patients with autoimmune thyroid disease. J Clin Endocrinol Metab 82: 666-669, 1997.

13. Ajjan RA and Weetman AP: Cytokines in thyroid autoimmunity. Autoimmunity 36: 351-359, 2003.

14. Xia N, Zhou S, Liang Y, et al: $\mathrm{CD}^{+} \mathrm{T}$ cells and the Th1/Th2 imbalance are implicated in the pathogenesis of Graves ophthalmopathy. Int J Mol Med 17: 911-916, 2006

15. Sakai K, Shirasawa S, Ishikawa N, et al: Identification of susceptibility loci for autoimmune thyroid disease to 5q31-q33 and Hashimoto's thyroiditis to 8q23-q24 by multipoint affected sib-pair linkage analysis in Japanese. Hum Mol Genet 10: 1379-1386, 2001.

16. Jin Y, Teng W, Ben S, et al: Genome-wide scan of Graves disease: evidence for linkage on chromosome $5 \mathrm{q} 31$ in Chinese Han pedigrees. J Clin Endocrinol Metab 88: 1798-1803, 2003.

17. Akamizu T, Hiratani H, Ikegami S, Rich SS and Bowden DW: Association study of autoimmune thyroid disease at 5q23-q33 in Japanese patients. J Hum Genet 48: 236-242, 2003.

18. Green SA, Cole G, Jacinto M, Innis M and Liggett SB: A polymorphism of the human beta 2-adrenergic receptor within the fourth transmembrane domain alters ligand binding and functional properties of the receptor. J Biol Chem 268: 23116-23121, 1993.

19. Green SA, Turki J, Bejarano P, Hall IP and Liggett SB: Influence of beta 2-adrenergic receptor genotypes on signal transduction in human airway smooth muscle cells. Am J Respir Cell Mol Biol 13: 25-33, 1995.

20. Turki J, Lorenz JN, Green SA, Donnelly ET, Jacinto M and Liggett SB: Myocardial signaling defects and impaired cardiac function of a human B2-adrenergic receptor polymorphism expressed in transgenic mice. Proc Natl Acad Sci USA 93: 10483-10488, 1996

21. Scott MG, Swan C, Wheatley AP and Hall IP: Identification of novel polymorphisms within the promoter region of the human beta2 adrenergic receptor gene. Br J Pharmacol 126: 841-844, 1999.

22. Drysdale CM, McGraw DW, Stack CB, et al: Complex promoter and coding region 32 -adrenergic receptor haplotypes alter receptor expression and predict in vivo responsiveness. Proc Natl Acad Sci USA 97: 10483-10488, 2000.

23. Liggett SB: Polymorphisms of the B2-adrenergic receptor and asthma. Am J Respir Crit Care Med 156: S156-S162, 1997.

24. Weir TD, Mallek N, Sandford AJ, et al: ß-2-adrenergic receptor haplotypes in mild, moderate and fatal/near fatal asthma. Am J Respir Crit Care Med 158: 787-791, 1998.

25. Heckbert SR, Hindorff LA, Edwards KL, et al: ß-2-adrenergic receptor polymorphisms and risk of incident cardiovascular events in the elderly. Circulation 107: 2021-2024, 2003. 
26. Busjahn A, Li G-H, Faulhaber H-D, et al: B2-adrenergic receptor gene variations, blood pressure, and heart size in normal twins. Hypertension 35: 555-560, 2000.

27. Forleo C, Resta N, Sorrentino S, et al: Association of betaadrenergic receptor polymorphisms and progression to heart failure in patients with idiopathic dilated cardiomyopathy. Am J Med 117: 451-458, 2004.

28. Bengtsson K, Orho-Melander M, Melander O, Lindblad U, Ranstam J, Rastam J and Groop L: B2-Adrenergic receptor gene variation and hypertension in subjects with type 2 diabetes. Hypertension 37: 1303-1308, 2001.

29. Bednarczuk T, Hiromatsu Y, Seki N, et al: Association of tumor necrosis factor and human leukocyte antigen DRB1 alleles with Graves ophthalmopathy. Hum Immunol 65: 632-639, 2004.

30. Werner SC: Modification of the classification of the eye changes of Graves disease: recommendation of the Ad Hoc Committee of the American Thyroid Association. J Clin Endocrinol Metab 44: 203-204, 1977.

31. Stephens M, Smith N and Donnelly P: A new statistical method for haplotype reconstruction from population data. Am J Hum Genet 68: 978-989, 2001.

32. Stephens M and Donnelly P: A comparison of Bayesian methods for haplotype reconstruction from population genotype data. Am J Hum Genet 73: 1162-1169, 2003.

33. Gordon D, Finch SJ, Nothnagel M and Ott J: Power and sample size calculations for case-control genetic association tests when errors present: application to single nucleotide polymorphisms. Hum Hered 54: 22-33, 2002.

34. Gordon D, Levenstien MA, Finch SJ and Ott J: Errors and linkage disequilibrium interact multiplicatively when computing sample sizes for genetic case-control association studies. Pacific Symp Biocomputing 8: 490-501, 2003.
35. Brix TH, Kyvik KO, Christensen $\mathrm{K}$ and Hegedus L: Evidence for a major role of heredity in Graves disease: a populationbased study of two Danish twin cohorts. J Clin Endocrinol Metab 86: 930-934, 2001

36. Ayadi H, Hadj Kacem H, Rebai A and Farid NR: The genetics of autoimmune thyroid disease. Trends Endocrinol Metab 15: 234-239, 2004.

37. Panina-Bordignon $\mathrm{P}$, Mazzeo D, Lucia PD, et al: Beta-2 agonists prevent Th1 development by selective inhibition of interleukin 12. J Clin Invest 100: 1513-1519, 1997.

38. Green S, Turki J, Innis M and Liggett SB: Amino-terminal polymorphisms of the human 32 -adrenergic receptor impart distinct agonist-promoted regulatory properties. Biochemistry 33: 9414-9419, 1994.

39. Liggett SB: Beta2-adrenergic receptor polymorphisms and sudden cardiac death: a signal to follow. Circulation 113: 1818-1820, 2006.

40. Sotoodehnia N, Siscovick DS, Vatta M, et al: Beta2-adrenergic receptor genetic variants and risk of sudden cardiac death. Circulation 113: 1842-1848, 2006.

41. Woszczek G, Borowiec M, Ptasinska A, Kosinski S, Pawliczak R and Kowalski ML: Beta2-ADR haplotypes/polymorphisms associate with bronchodilator response and total $\operatorname{IgE}$ in grass allergy. Allergy 60: 1412-1417, 2005

42. Narkiewicz K, van de Borne PJH, Hausberg M, Cooley RL, Winniford MD, Davison DE and Somers VK: Cigarette smoking increases sympathetic outflow in humans. Circulation 98: 528-534, 1998.

43. Leineweber K and Brodde OE: Beta2-adrenoceptor polymorphisms: relation between in vitro and in vivo phenotypes. Life Sci 74: 2803-2814, 2004. 